\title{
Association Between Mannose-binding Lectin Gene Polymorphisms and Necrotizing Enterocolitis in Preterm Infants
}

\author{
${ }^{*}$ Giusi Prencipe, ${ }^{\dagger}$ Chiara Azzari, ${ }^{\dagger}$ Maria Moriondo, ${ }^{\ddagger}$ Rita Devito, ${ }^{\S}$ Rita Inglese, ${ }^{\|}$Marco Pezzullo, \\ ${ }^{\top}$ Fiammetta Piersigilli, ${ }^{\top}$ Alessandro Trucchi, *Fabrizio De Benedetti, and ${ }^{\top}$ Cinzia Auriti
}

\begin{abstract}
Objectives: The aim of the present study was to evaluate whether polymorphisms of the mannose-binding lectin $(M B L-2)$ gene and $\mathrm{MBL}$ serum levels on admission to neonatal intensive care unit are associated with necrotizing enterocolitis (NEC) in preterm infants and to verify MBL expression in NEC bowels.

Methods: In this retrospective cohort study, 107 neonates (41 with NEC and 66 controls) were included. $M B L-2$ genotyping for the promoter polymorphism -221 and for the exon 1 variant alleles at codons 52, 54, and 57 was performed. MBL levels were determined by enzymelinked immunosorbent assay in 55 infants. Immunohistochemical staining for MBL expression was performed on bowel specimens. The main study outcome was severe NEC (Bell stages II/III).

Results: The $-221 \mathrm{Y}$ allele and the $M B L-2$ YY genotype were more frequent in neonates with severe NEC than in controls $(P=0.04$ and $P=0.004$, respectively). In the multivariate analysis, the $M B L-2 \mathrm{YA} / \mathrm{YA}$ genotype was associated with NEC (odds ratio $=3.03,95 \%$ confidence interval $1.13 \%-8.13 \%, P=0.024)$. Neonates with NEC had MBL level on admission $>400 \mathrm{ng} / \mathrm{mL}$ more frequently than controls $(P=0.043)$. Among neonates with severe NEC, the deceased neonates were carriers of high or intermediate producing $M B L-2$ genotypes $(P=0.035)$. Finally, MBL was highly expressed in intestinal tissue from infants with NEC.

Conclusions: $M B L-2$ genotypes associated with high MBL serum levels represent a risk factor for NEC. This finding, together with the MBL expression in bowel tissue, supports a role for MBL in the pathogenesis of NEC.
\end{abstract}

Received September 29, 2011; accepted February 2, 2012.

From the *Laboratory of Rheumatology, Bambino Gesù Children's Hospital, Rome, the †Department of Pediatrics, Anna Meyer Children's University Hospital, Firenze, the ‡Division of Pathology, the §Clinical Chemistry Laboratory, the l|Core Facilities, and the Department of Medical and Surgical Neonatology, Bambino Gesù Children's Hospital, Rome, Italy.

Address correspondence and reprint requests to Cinzia Auriti, MD, Department of Neonatology, Neonatal Intensive Care Unit, Bambino Gesù Children's Hospital, 00165 Piazza S. Onofrio 4, 00165 Rome, Italy (e-mail: cinzia.auriti@opbg.net).

The study was supported by the Health Department of the Italian Government (Italian Ministry of Health: Grant 200602P/001751) and by Bambino Gesù Children's Hospital.

The authors report no conflicts of interest.

Copyright (1) 2012 by European Society for Pediatric Gastroenterology, Hepatology, and Nutrition and North American Society for Pediatric Gastroenterology, Hepatology, and Nutrition

DOI: 10.1097/MPG.0b013e31824e5f7a
Key Words: mannose-binding lectin, $M B L-2$ gene, necrotizing enterocolitis, preterm infants

(JPGN 2012;55: 160-165)

$\mathrm{N}$ ecrotizing enterocolitis (NEC) is the most common and serious gastrointestinal disorder among preterm infants. It is a leading cause of morbidity and mortality: approximately $12 \%$ of premature infants weighing $<1500 \mathrm{~g}$ will become afflicted with NEC, and about one-third of them will succumb to the disease. Although prematurity, gut motility, intestinal impaired blood flow, formula feeding, and bacterial colonization have been implicated, the pathogenesis of NEC remains unclear (1). Numerous data suggest that the unifying hypothesis between these pathogenetic factors could be the uncontrolled exuberant inflammatory response to bacterial colonization together with the inadequate anti-inflammatory response observed in the immature intestine (1).

The innate immune system represents the first line of defense before the neonates can mount an appropriate adaptive immune response (2). Mannose-binding lectin (MBL) is a receptor of the innate immune system. It is particularly important because it binds and opsonises a variety of pathogens and activates the lectin pathway of complement, providing rapid protection against microbial invasion (3). MBL serum levels are genetically determined (4). Three structural single nucleotide polymorphisms (SNPs) of the $M B L-2$ gene exon 1 , at codons 52, 54, and 57, interfere with the assembly of the protein, causing decreased functional MBL levels. In addition, the $-221 \mathrm{X} / \mathrm{Y}$ promoter SNP affects the protein expression, the $-221 \mathrm{Y}$ variant being associated with higher MBL levels (5). Human MBL is characteristically produced by hepatocytes, but an extrahepatic transcription in the human intestine has also been described, suggesting that MBL expression may participate in the local immune defense in this site (6).

We hypothesized that MBL may have a role in intestinal injury during NEC and that SNPs of the $M B L-2$ gene related to high MBL expression could be a risk factor for severe NEC. Therefore, we have investigated whether SNPs of the $M B L-2$ gene and high serum MBL levels were associated with severe NEC in a retrospective cohort of preterm infants admitted to our neonatal intensive care unit (NICU).

To further support the relation between the induction of the proinflammatory response and the intestinal tissue injury, we have also examined the expression of MBL in biopsy bowel sections from preterm neonates who underwent surgery during NEC. 


\section{METHODS}

\section{Patients}

This retrospective cohort study comprised 107 neonates, with a gestational age (GA) of $\leq 32$ weeks, consecutively admitted to our NICU between January 2005 and December 2008. Among these neonates, 41 had NEC and 66 were not affected. Among 41 neonates with NEC, $33(80.5 \%)$ developed the disease during hospitalization in our unit and $8(19.5 \%)$ were referred to our NICU because of either suspected or overt NEC. A whole-blood sample was collected for the 107 neonates enrolled, together with informed consent from parents, for genetic analysis. From 55 of 107 neonates, a serum sample was collected on admission to the NICU (median day of life 1; interquartile range [IQR] 1-8) for measurement of MBL levels. Serum samples were not obtained from neonates with symptoms of infection or suspected or overt NEC.

Patients' characteristics and clinical data were searched retrospectively, using the neonatal database of the unit and the patients' charts. The following demographic and clinical characteristics on admission to the NICU were recorded: sex, birth weight (BW), GA, prenatal steroids exposure, mode of delivery, Apgar score at $5^{\prime}$, need for intubation and ventilation at birth, mode of delivery, presence of respiratory distress syndrome, patent ductus arteriosus beyond the third day of life, and development of infections during hospitalization.

NEC was defined according to the Bell classification system (7). For the analysis, "severe NEC" definition included Bell stages II and III, and "NEC" included Bell stages I, II, and III.

\section{MBL-2 Genotyping}

Genomic DNA was extracted from ethylenediaminetetraacetic acid blood samples using QIAmp DNA Blood kit (Qiagen, Hilden, Germany). Typing of the $M B L$ gene exon 1 (mutant codons 52, 54, and 57) and promoter (position -221) was performed by polymerase chain reaction and restriction fragment length polymorphism. For exon 1, the wild-type allele was designated as A, whereas B, C, and D were, respectively, mutants in codon 54, 57, and 52. For the promoter, the wild-type allele was designated as $\mathrm{Y}$ (position -221), whereas $\mathrm{X}$ was the mutant. The $3 \mathrm{MBL}-2$ structural gene mutations $\mathrm{B}, \mathrm{C}$, and D (collectively referred as $\mathrm{O})$ are in linkage disequilibrium with the promoter region polymorphism $\mathrm{X} / \mathrm{Y}$, so that only $\mathrm{Y}$ associates with variant alleles (5). According to Garred et al (8), we grouped $M B L-2$ genotypes in high (YA/YA), intermediate (YA/XA, XA/XA), and low/deficient (YA/YO, YO/XA, YO/YO) MBL-expressing groups.

\section{Measurement of MBL}

Serum MBL was measured using an immunoassay (MBL oligomer ELISA, Antibody Shop, Copenhagen, Denmark) according to the instruction provided by the manufacturer. The linear range was 0.25 to $40 \mathrm{ng} / \mathrm{mL}$. Sera were diluted 1:300 in the sample diluent provided by the manufacturer. The lowest detectable MBL concentration was $0.075 \mathrm{ng} / \mathrm{mL}$. Results below the limit of detection were allocated a value of $0.05 \mathrm{ng} / \mathrm{mL}$ for statistical purposes.

\section{MBL Immunohistochemistry}

Intestinal specimens were obtained from infants with NEC stage III who underwent surgical bowel resection $(n=9)$. Both necrotic and perilesional areas were examined. Moreover, healthy intestinal specimens were obtained from patients who previously had NEC and underwent ileostomy $(\mathrm{n}=12)$, as well as from age-matched patients $(\mathrm{n}=3)$, who underwent ileostomy because of Meckel diverticulum. Intestinal tissue was fixed in neutral buffered formalin and embedded in paraffin. After moist heat-induced antigen retrieval with $1 \mathrm{mmol} / \mathrm{L}$ ethylenediaminetetraacetic acid at $\mathrm{pH} 9.0,3-\mu \mathrm{m}$ sections were incubated with a mouse monoclonal antibody to human MBL (Santa Cruz Biotech, Santa Cruz, CA) for 1 hour at room temperature or with an irrelevant mouse immunoglobulin G1. After washing, the presence of MBL was revealed with the labeled Streptavidin-Biotin2 System (Dako Cytomation, Carpinteria, CA), based on the use of a biotinylated secondary antibody and peroxidase conjugated streptavidin. The procedure was in accordance with the instructions of the manufacturer. 3-3' Diaminobenzidine was used as a chromogen and counterstaining was done with hematoxylin (Dako Cytomation).

\section{Statistical Analysis}

For the statistical analyses, we used the Statistical Package for Social Sciences (SPSS Inc, Chicago, IL) and STATA (StataCorp, College Station, TX). Quantitative data were expressed as medians and IQRs, and frequencies were compared by the $\chi^{2}$ test or the Fisher exact test. For the genotype frequency analysis of the promoter $-221 \mathrm{XY}$, we classified patients into 2 groups: those carrying at least 1 MBL-221 $\mathrm{X}$ allele (XY and XX) and those carrying the $\mathrm{YY}$ genotype because only 1 patient was a carrier of the XX genotype.

We performed uni- and multivariate logistic regression analyses: the main outcome was the occurrence of NEC (severe NEC and NEC). All of the variables associated with the risk of NEC in univariate analyses with $P<0.05$ were included in the multivariate analysis. $P<0.05$ was considered significant.

\section{RESULTS}

\section{Patients' Characteristics}

Among 107 preterm neonates included in the study, 41 were affected by NEC (stage I, $\mathrm{n}=20$; stage II, $\mathrm{n}=3$; and stage III, $\mathrm{n}=18$ ) and 66 were not affected (controls). Neonates with NEC were analyzed as 2 groups: severe NEC (stages II and III) and NEC (stages I, II, and III) and compared with controls. Table 1 shows the clinical characteristics of the patients: low GA, low BW, confirmed infections, and death were more frequent in severe NEC neonates compared with controls.

\section{Analysis of $M B L-2$ Genotype and Association With NEC}

We have genotyped 4 common SNPs of the $M B L-2$ gene: codons 52, 54, and 57 in the exon 1 and -221 in the promoter region. Allele and genotype frequencies for all of the studied SNPs are summarized in Table 2 . The frequency of the promoter $-221 \mathrm{Y}$ allele was higher in patients with severe NEC than in controls $(P=0.04)$. Moreover, neonates with severe NEC showed an increased probability of carrying the YY genotype compared with controls (odds ratio [OR] 5.1, 95\% confidence interval [CI] 1.55\%$16.8 \% ; P=0.004)$. Conversely, the allelic frequencies of the exon 1 polymorphisms $\mathrm{C}$ and $\mathrm{B}$ were similar in neonates with severe NEC and in control neonates; we did not found neonates with the D variant allele. Naming " $O$ " the $M B L-2$ structural variant alleles $\mathrm{B}$ and $\mathrm{C}$, the frequency of $\mathrm{AA}, \mathrm{AO}$, and $\mathrm{OO}$ genotypes between neonates with severe NEC and controls was similar.

At the genotypic analysis, the frequency of the highMBL-level related YA/YA genotype was increased in neonates with severe NEC compared with controls (OR 3.03, 95\% CI 
TABLE 1. Clinical characteristics and procedures in neonates with severe NEC (stages II-III), NEC (stages I, II, and III), and in neonates without NEC (controls)

\begin{tabular}{|c|c|c|c|c|c|}
\hline $\begin{array}{l}\text { Clinical characteristic } \\
\text { and procedures }\end{array}$ & $\begin{array}{l}\text { Controls, } \\
\mathrm{n}=66\end{array}$ & $\begin{array}{l}\text { Severe NEC, } \\
\quad \mathrm{n}=21\end{array}$ & $P^{*}$ & $\begin{array}{l}\mathrm{NEC}, \\
\mathrm{n}=41\end{array}$ & $P^{*}$ \\
\hline White ethnicity, \% & 93.9 & 90.5 & $\mathrm{NS}^{\dagger}$ & 92.7 & NS \\
\hline Male sex, $\%$ & 50.0 & 42.9 & NS & 51.2 & NS \\
\hline Gestational age, wk ${ }^{\ddagger}$ & $28(26-30)$ & $26(25-29)$ & 0.02 & $27(26-29)$ & 0.07 \\
\hline Birth weight, $\mathrm{g}^{\ddagger}$ & $1165(830-1360)$ & $880(638.75-1063.75)$ & 0.04 & $910(737.5-1107.5)$ & 0.01 \\
\hline Small for gestational age, $\%$ & 7.6 & 19.0 & NS & 17.1 & NS \\
\hline Prenatal steroids, \% & 69.7 & 52.6 & NS & 58.5 & NS \\
\hline Cesarean section, $\%$ & 75.7 & 61.9 & NS & 68.3 & NS \\
\hline Apgar $5^{\prime} \leq 5, \%$ & 18.2 & 14.3 & NS & 14.6 & NS \\
\hline Orotracheal intubation, $\%$ & 18.2 & 28.6 & NS & 24.4 & NS \\
\hline Respiratory distress syndrome, $\%$ & 90.9 & 100 & NS & 95.1 & NS \\
\hline Surfactant administration, $\%$ & 75.7 & 84.2 & NS & 73.2 & NS \\
\hline Patent ductus arteriosus, $\%$ & 50.0 & 66.7 & NS & 68.3 & NS \\
\hline Infection $^{\S}, \%$ & 53.0 & 80.0 & 0.02 & 58.5 & NS \\
\hline Death, \% & 7.6 & 52.4 & $<0.001$ & 29.3 & 0.003 \\
\hline
\end{tabular}

$\mathrm{NEC}=$ necrotizing enterocolitis. ${ }^{*} \chi^{2}$ test. ${ }^{\dagger}$ Not significant. ${ }^{\ddagger}$ Continuous variables are reported as median and IQR. ${ }^{\S}$ Confirmed infections diagnosed before the development of NEC in cases and during the whole hospitalization in controls.

$1.13 \%-8.13 \%, P=0.024)$ (Table 3). When we looked at all of the neonates with NEC (stages I, II, and III), the allele and genotype frequencies of the considered SNPs were similar to those observed in neonates with severe NEC. At univariate analysis, GA and infections were significantly associated with severe NEC. At multivariate analysis, with $\mathrm{GA}, \mathrm{BW}$, and infections as covariates, the YA/YA genotype remained independently associated with severe NEC (OR $4.42,95 \%$ CI $1.11 \%-17.49 \%, P=0.03$ ) or with NEC

TABLE 2. Distribution of allele and genotype frequencies of 4 SNPs in the MBL-2 gene among severe NEC neonates (stages II and III), NEC neonates (stages I, II, and III), and controls

\begin{tabular}{|c|c|c|c|c|c|}
\hline & $\begin{array}{c}\text { Controls, } \\
n=66\end{array}$ & $\begin{array}{c}\text { Severe NEC, } \\
n=21\end{array}$ & $\begin{array}{c}\text { OR }(95 \% \mathrm{CI}) \\
P\end{array}$ & $\begin{array}{l}\text { NEC, } \\
\mathrm{n}=41\end{array}$ & $\begin{array}{c}\text { OR }(95 \% \mathrm{CI}) \\
P\end{array}$ \\
\hline \multicolumn{6}{|l|}{ Alleles } \\
\hline \multicolumn{6}{|c|}{$-221 \mathrm{G} \rightarrow \mathrm{C}$ (allele $\mathrm{X}$ ) } \\
\hline G & $96(72.7)$ & $38(90.5)$ & \multirow[t]{2}{*}{$2.78(1.01 \%-7.6 \%) ; 0.04$} & $71(86.6)$ & \multirow[t]{2}{*}{$2.42(1.15 \%-5.08 \%) ; 0.017$} \\
\hline $\mathrm{C}$ & $36(27.3)$ & $4(9.5)$ & & $11(13.4)$ & \\
\hline \multicolumn{6}{|c|}{ Codon $54 \mathrm{G} \rightarrow \mathrm{A}$ (allele $\mathrm{B}$ ) } \\
\hline G & $110(83.3)$ & $37(88.1)$ & \multirow[t]{2}{*}{ NS } & $73(89.0)$ & \multirow[t]{2}{*}{ NS } \\
\hline $\mathrm{A}$ & $22(16.7)$ & $5(11.9)$ & & $9(11.0)$ & \\
\hline \multicolumn{6}{|c|}{ Codon $57 \mathrm{G} \rightarrow \mathrm{A}$ (allele $\mathrm{C}$ ) } \\
\hline $\mathrm{G}$ & $130(98.5)$ & $41(97.6)$ & \multirow[t]{2}{*}{ NS } & $80(97.6)$ & \multirow[t]{2}{*}{ NS } \\
\hline A & $2(1.5)$ & $1(2.3)$ & & $2(2.4)$ & \\
\hline \multicolumn{6}{|c|}{ Structural exon 1 genotypes } \\
\hline AA & $45(68.2)$ & $17(81.0)$ & \multirow[t]{3}{*}{ NS } & $32(78)$ & \multirow[t]{3}{*}{ NS } \\
\hline $\mathrm{AO}$ & $18(27.3)$ & $2(9.5)$ & & $7(17.1)$ & \\
\hline $\mathrm{OO}$ & $3(4.5)$ & $2(9.5)$ & & $2(4.9)$ & \\
\hline
\end{tabular}

Data are expressed as number and (\%). $\mathrm{CI}=$ confidence interval; $\mathrm{MBL}=$ mannose-binding lectin; $\mathrm{NEC}=$ necrotizing enterocolitis; OR $=$ odd ratio; $\mathrm{SNP}=$ single nucleotide polymorphism . 


\begin{tabular}{|c|c|c|c|c|c|}
\hline$M B L-2$ genotype & $\begin{array}{c}\text { Controls, } \\
n=66\end{array}$ & $\begin{array}{c}\text { Severe NEC, } \\
n=21\end{array}$ & $\begin{array}{c}\text { OR }(95 \% \mathrm{CI}) \\
P\end{array}$ & $\begin{array}{c}\text { NEC } \\
\mathrm{n}=41\end{array}$ & $\begin{array}{c}\text { OR }(95 \% \mathrm{CI}) \\
P\end{array}$ \\
\hline \multicolumn{6}{|l|}{ High MBL group } \\
\hline YA/YA & $19(28.8)$ & $13(61.9)$ & $3.03(1.13 \%-8.13 \%) ; 0.024$ & $24(58.5)$ & $3.49(1.54 \%-7.92 \%) ; 0.002$ \\
\hline \multicolumn{6}{|c|}{ Intermediate MBL group } \\
\hline $\mathrm{YA} / \mathrm{XA}+\mathrm{XA} / \mathrm{XA}$ & $26(39.4)$ & $4(19.0)$ & NS & $8(19.5)$ & NS \\
\hline \multicolumn{6}{|l|}{ Low MBL group } \\
\hline $\mathrm{YA} / \mathrm{YB}+\mathrm{YC}$ & $9(13.6)$ & $2(9.5)$ & NS & $6(14.6)$ & NS \\
\hline $\mathrm{XA} / \mathrm{YB}+\mathrm{YC}$ & $9(13.6)$ & 0 & & $1(2.4)$ & \\
\hline $\mathrm{YO} / \mathrm{YO}$ & $3(4.5)$ & $2(9.5)$ & & $2(4.9)$ & \\
\hline
\end{tabular}

$\mathrm{CI}=$ confidence interval; $\mathrm{MBL}=$ mannose-binding lectin; $\mathrm{NEC}=$ necrotizing enterocolitis; $\mathrm{OR}=$ odds ratio.

(stages I-II and III) (OR 3.48, 95\% CI 1.22\%-9.94\%; $P=0.02$ ). Similar results were obtained eliminating from the cohort all nonwhite neonates (data not shown), excluding the possibility that the inclusion of these neonates could lead to a bias.

We did not observe a significant difference in the frequency of the YA/YA carriers between deceased and survived infants (data not shown); however, all 11 deceased neonates with severe NEC carried a high or intermediate $M B L-2$ genotype. Conversely, 4 of the 10 survivors were low/deficient genotype carriers $(\mathrm{YA} / \mathrm{YO}$ or $\mathrm{XA} / \mathrm{YO}$ or $\mathrm{YO} / \mathrm{YO} ; P=0.035$, by Fisher exact test).

\section{Serum MBL Levels on Admission and Association With NEC}

A serum sample collected on admission to the NICU, in the absence of symptoms of infection, was available from 55 of 107 neonates enrolled in the study. Twenty of these 55 neonates subsequently developed NEC (stage I, $\mathrm{n}=12$; stage $2, \mathrm{n}=1$; stage III, $\mathrm{n}=7$ ) during hospitalization. Neonates with and without NEC were similar in baseline characteristics, with exception of BW, which was lower, but not significantly, in neonates with NEC than in the others (median BW $905 \mathrm{~g}$, IQR 805-1105 vs $1176 \mathrm{~g}$, IQR $841.25-1537.5 ; P=0.08)$.

MBL levels on admission to the NICU were determined in sera from all 55 neonates. MBL values were stratified by structural exon 1 genotypes (AA, AO, and OO). As expected, we observed high, medium, and low values, respectively $(P<0.01)$. Subdividing these genotypes by the -221 SNP, we observed a trend toward higher serum MBL levels in the YY carriers compared with XY carriers (median value $1.13 \mu \mathrm{g} / \mathrm{mL}$, IQR $0.28-2.33$ vs median value $0.85 \mu \mathrm{g} / \mathrm{mL}$, IQR $0.17-1.80 ; P=0.2$ ).

Based on previous investigations in preterm neonates $(9,10)$, we set the cutoff value to $400 \mathrm{ng} / \mathrm{mL}$ to discriminate $\mathrm{MBL}$ deficiency. We observed that 8 of $8(100 \%)$ neonates with severe NEC (stages II and III) had MBL level $>400 \mathrm{ng} / \mathrm{mL}$ on admission to the NICU. Among neonates who did not develop NEC during hospitalization, 19 of $35(54.3 \%)$ had MBL levels $>400 \mathrm{ng} / \mathrm{mL}$ on admission to the NICU (Fisher exact test, $P=0.043$ ). This difference was also evident in all of the neonates with NEC: 18 of $20(90 \%)$ neonates with NEC at stages I, II, and III had MBL serum levels $>400 \mathrm{ng} / \mathrm{mL}$ (OR 7.58, 95\% CI 1.52\%-37.3\%; $P=0.007)$. Finally, in a multivariate model of analysis, MBL levels $>400 \mathrm{ng} / \mathrm{mL}$ remained associated with NEC (OR 8.3, 95\% CI $1.6 \%-42.6 \% ; P=0.01$ ) after adjusting for GA.

\section{MBL Expression in the Intestine of Infants With NEC}

To confirm the functional association of MBL with development of NEC, we investigated whether MBL was expressed in the intestinal tissue of preterm infants. Immunohistochemical staining with an anti-MBL antibody was performed on intestinal biopsy specimens obtained from infants with NEC during bowel surgical resection. The analysis revealed that $\mathrm{MBL}$ is highly expressed in intestinal tissue from infants with NEC. In particular, MBL is expressed in diseased mucosa, in endothelial cells, and in histiocytes of the small intestine (Fig. 1A-C) and of the proximal colon (data not shown). MBL expression was also evident in enterocytes of perilesional uninvolved bowel segments of the same patients (data not shown). Moreover, MBL expression was observed in enterocytes of healthy bowel biopsy sections obtained during surgery for ileostomy from patients, not deficient in MBL expression, who previously had NEC (Fig. 1D-F) or who underwent ileostomy because of Meckel diverticulum (data not shown). As negative control for the immunohistochemical analysis, we performed MBL staining on intestinal tissue obtained during surgical ileostomy from a NEC preterm patient who, being OO homozygous, was MBL deficient (Fig. 1G-I).

\section{DISCUSSION}

Evidence indicates that an abnormal response by the premature infant to the microbial flora that colonizes the gastrointestinal tract may be involved in the pathogenesis of NEC. Indeed, a stronger interleukin-8-driven proinflammatory response is provoked in immature intestinal cells when exposed to commensal organisms (11). Several proinflammatory cytokines, including interleukin- 6 and tumor necrosis factor- $\alpha$, have also been found in intestinal samples of infants with NEC (12). Recent studies demonstrate that Toll-like receptors (TLRs) could be central players in the pathways that signal in response to enteric bacteria, favoring the development of NEC $(13,14)$. Moreover, microarray analysis shows that in the immature intestine, the expression of genes involved in upregulation of inflammation is increased, whereas the expression of negative regulators of inflammation is decreased (15). It is therefore reasonable to hypothesize that the onset of an uncontrolled inflammatory response by the neonatal intestine to exposure to luminal bacteria may trigger the onset of NEC.

As TLRs, MBL is a pattern recognition receptor (PRR) and plays an important role in innate immune system, coordinating, amplifying, and synchronizing innate immune defense mechanisms 


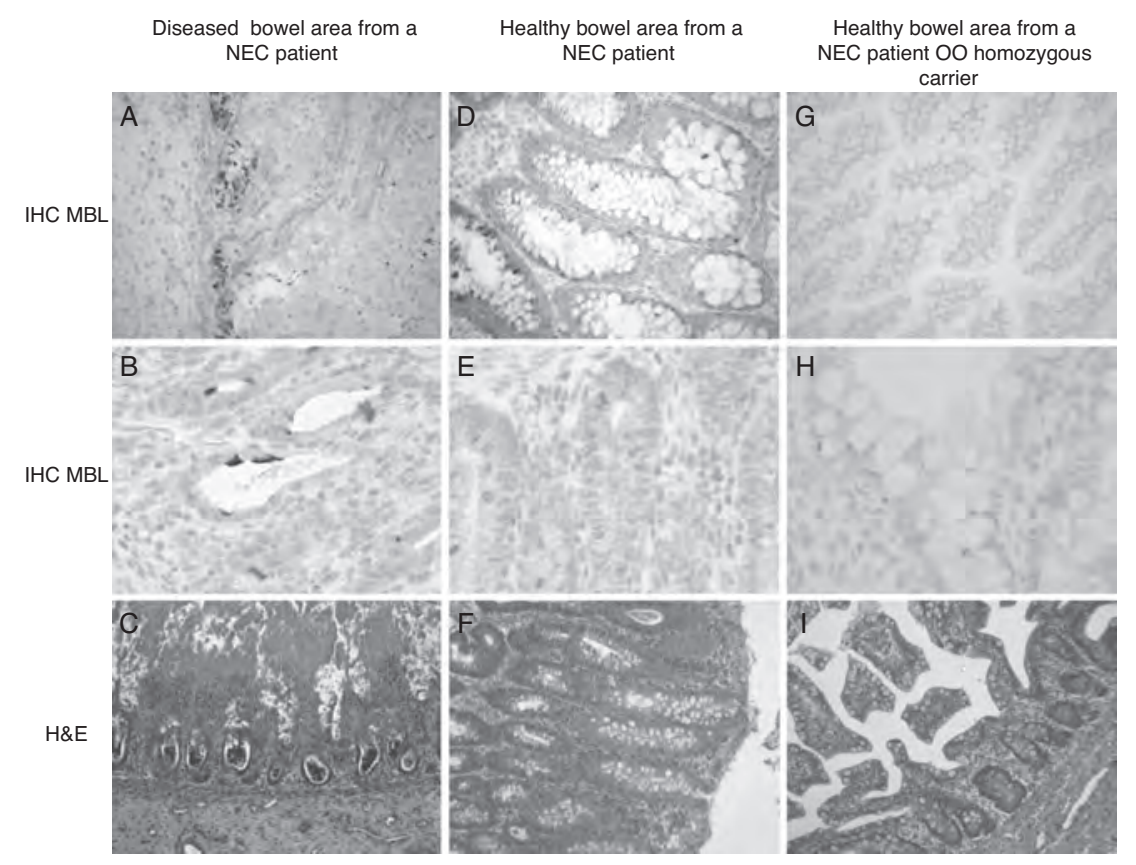

FIGURE 1. Histologic and immunohistochemical analyses of mannose-binding lectin (MBL) expression in diseased and normal bowel areas from preterm infants who underwent surgery for NEC. Tissue sections from the ileum were analyzed for morphological integrity by $\mathrm{H} \& \mathrm{E}$ staining $(C, F, I)$ and by immunohistochemistry to detect expression of $M B L(A, B, D, E, G$, $H)$. (A, B) Representative diseased ileum sections from a preterm neonate with NEC who underwent surgical resection. Strong staining for MBL was detected in enterocytes, endothelial cells, and histiocytes. (D, E) Representative control ileum sections from a preterm neonate who underwent ileostomy. Positive staining for MBL was found in enterocytes. (G-H) Representative diseased ileum sections from a preterm neonate with necrotizing enterocolitis (NEC) who was deficient in the production of functional MBL (OO homozygous carrier for the exon $1 \mathrm{MBL}-2$ genotype) and who underwent ileostomy. Negative staining for MBL was observed. Original magnification $\times 20$ for $A, D, G, \times 40$ for $B, E, H$, and $\times 10$ for $C, F, I$.

(3). Indeed, MBL, together with the MBL-associated serine proteases, initiate the lectin pathway of the complement system. Moreover, it has been established that MBL has a central role in regulating PRR signaling and inflammatory cytokine production, acting as a TLR-2/6 co-receptor $(16,17)$.

In the present study, we found that the -221 promoter $M B L$ 2 variant allele $Y$, being associated with higher serum MBL levels, is significantly more common in neonates with NEC than in control neonates. Moreover, we observed a significant association of the -221 YY promoter genotype and of the combined exon 1/promoter $-221 \mathrm{YA} / \mathrm{YA}$ genotype, both causing high MBL protein levels, with a higher risk of developing NEC, independently from GA. Interestingly, we observed that $M B L-2$ genotypes related to low MBL levels were associated with a decreased mortality among neonates with severe NEC, suggesting that MBL levels may affect the outcome of NEC and further supporting the hypothesis of a role of high MBL levels in contributing to intestinal damage. We also found that neonates with NEC had MBL serum levels $>400 \mathrm{ng} / \mathrm{mL}$ on admission to the NICU more frequently than controls without NEC. Our observations on serum MBL levels complement the findings of a recent study (18): high MBLassociated serine protease- 2 cord blood levels have been found to be associated with an increased risk of NEC in preterm neonates. It should be noted that, in the same study, the authors did not find an association between MBL cord blood levels and NEC. This may be because they measured MBL cord blood levels and not serum MBL levels. Cord blood MBL levels may not reflect MBL levels in the first days of life (19).
MBL is expressed by hepatocytes, but recent evidence in mice indicates an extrahepatic expression in small intestine, in which MBL-C is expressed by villous epithelial cells (20). In humans, Seyfarth et al (6) observed low extrahepatic levels of $M B L-2$ mRNA, predominantly in small intestine. We detected the expression of MBL protein in the diseased guts of preterm infants with NEC: MBL was strongly expressed in enterocytes, in endothelial cells, and in histiocytes of the small intestine and colon. Moreover, we observed a positive staining for MBL also in enterocytes of intestinal tissues from healthy infants. It should be noted that we did not detect any staining in the intestinal tissue from an MBL-deficient infant. Our results are in apparent contrast to the negligible MBL expression reported in the intestinal mucosa of both adult healthy controls and patients with Crohn disease (21). The discrepancy between these data and our results in neonates may be related to the age of the patients. Indeed, the gastrointestinal tract of the premature infant differs largely from that of an adult. It has a fragile surface area covered by a thin monolayer of epithelial cells that overlies a highly immunoreactive mucosa, and there is accumulating evidence that in the newborn, especially in the premature neonate, the defense mechanism that normally maintains a healthy balance in intestine may be inadequate, or at least functioning at different levels compared with what occurs in adults (1). This is also supported by the previously mentioned gene expression profile data (15). Therefore, these data sustain the hypothesis that in neonates, MBL could be an important factor in intestinal immunity, contributing to local innate defense and that the local production of MBL may be biologically relevant. 
Our results suggest that genetically determined high MBL production is an independent risk factor for the development of NEC, further supporting the hypothesis that PRRs of innate immunity and their mediators could be important players in the initiation of an exaggerated inflammatory response, ultimately leading to intestinal injury. Moreover, these results support the emerging hypothesis of a dual role for MBL: Low MBL levels would not be disadvantageous, but, in some circumstances, also confer a benefit (22). Although an increased susceptibility to infections has been reported in MBL-deficient patients, including premature infants $(23,24)$, other studies support a role for MBL in ischemiareperfusion injury $(25,26)$, with high MBL levels associated with more severe disease. Interestingly, ischemia and reperfusion injury has emerged as a possible cause of NEC (27).

The relatively small sample size is the main limitation of the present study. Future studies on larger groups of preterm infants may be needed to clarify the role of the lectin pathway during the neonatal age in determining the high susceptibility of this population to NEC. Moreover, we did not genotypize the $4 \mathrm{P} / \mathrm{Q}$ and $-550 \mathrm{H} / \mathrm{L} M B L-2$ SNPs; however, the polymorphism at position -221 in the promoter region of the gene induces the strongest upregulating ( $\mathrm{Y}$ variant) effect, and it is marginally influenced by the 4 and -550 SNPs (4).

In conclusion, this is the first study to our knowledge that explores the potential association among $M B L-2$ genotype, MBL serum levels, and development of NEC in preterm neonates. We report that MBL genotypes, which are associated with high serum MBL levels, were significantly more common in neonates with NEC than in controls; neonates with NEC had MBL serum levels $>400 \mathrm{ng} / \mathrm{mL}$ on admission to the NICU more frequently than controls without NEC; neonates with severe NEC carrying lowexpressing $M B L-2$ genotypes had a smaller probability of death; and MBL is highly expressed in healthy intestinal tissue and in intestinal biopsy specimens from infants with NEC. Our findings add to the knowledge that genetic factors, leading to an overexpression of MBL, may be involved in the pathway causing NEC and may influence its outcome in preterm neonates; however, it is likely that other polymorphisms exist at multiple points in genes regulating the inflammatory cascade, which may account for individual susceptibility in the development of NEC. Genetic analysis of the $M B L-2$ gene polymorphisms may help to identify subsets of premature infants at risk of developing NEC and subsets of infants with NEC at risk of severe outcome. Finally, because recombinant human MBL is being developed as a therapeutic approach (28), studies aimed at investigating the role of MBL in the neonatal period may be useful to understand whether its administration may be beneficial (possibly lowering risk of infections) or rather dangerous in this delicate age group.

\section{REFERENCES}

1. Neu J, Chen M, Beierle E. Intestinal innate immunity: how does it relate to the pathogenesis of necrotizing enterocolitis. Semin Pediatr Surg 2005; 14:137-44.

2. Marodi L. Neonatal innate immunity to infectious agents. Infect Immunity 2006;74:1999-2006.

3. Ip WK, Takahashi K, Ezekowitz RA, et al. Mannose-binding lectin and innate immunity. Immunol Rev 2009;230:9-21.

4. Garred P, Larsen F, Seyfarth J, et al. Mannose-binding lectin and its genetic variants. Genes Immun 2006;7:85-94.

5. Madsen HO, Garred P, Thiel S, et al. Interplay between promoter and structural gene variants control basal serum level of mannan-binding protein. J Immunol 1995;155:3013-20.
6. Seyfarth J, Garred P, Madsen HO. Extra-hepatic transcription of the human mannose-binding lectin gene (mbl2) and the MBL-associated serine protease 1-3 genes. Molec Immunol 2006;43:962-71.

7. Bell MJ. Neonatal necrotizing enterocolitis. N Engl J Med 1978; 298:281-2.

8. Garred P, Larsen F, Madsen HO, et al. Mannose-binding lectin deficiency-revisited. Molec Immunol 2003;40:73-84.

9. Lau YL, Chan SY, Turner MW, et al. Mannose-binding protein in preterm infants: developmental profile and clinical significance. Clin Exp Immunol 1995;102:649-54.

10. Dzwonek AB, Neth OW, Thiebaut R, et al. The role of mannose-binding lectin in susceptibility to infection in preterm neonates. Pediatr Res 2008;63:680-5.

11. Claud EC, Lu L, Anton PM, et al. Developmentally regulated IkappaB expression in intestinal epithelium and susceptibility to flagellininduced inflammation. Proc Natl Acad Sci U S A 2004;101:7404-8.

12. Harris MC, Costarino AT Jr, Sullivan JS, et al. Cytokine elevations in critically ill infants with sepsis and necrotizing enterocolitis. J Pediatr 1994;124:105-11.

13. Le Mandat Schultz A, Bonnard A, Barreau F, et al. Expression of TLR2, TLR-4, NOD2 and pNF-kappaB in a neonatal rat model of necrotizing enterocolitis. PloS One 2007;2:e1102.

14. Liu Y, Zhu L, Fatheree NY, et al. Changes in intestinal toll-like receptors and cytokines precede histological injury in a rat model of necrotizing enterocolitis. Am J Physiol Gastrointest Liver Physiol 2009;297: G442-50.

15. Nanthakumar N, Meng D, Goldstein AM, et al. The mechanism of excessive intestinal inflammation in necrotizing enterocolitis: an immature innate immune response. PloS One 2011;6:e17776.

16. Ip WK, Takahashi K, Moore KJ, et al. Mannose-binding lectin enhances toll-like receptors 2 and 6 signaling from the phagosome. J Exp Med 2008;205:169-81.

17. Shimizu T, Nishitani C, Mitsuzawa H, et al. Mannose binding lectin and lung collectins interact with Toll-like receptor 4 and MD-2 by different mechanisms. Biochim Biophys Acta 2009;1790:1705-10.

18. Schlapbach LJ, Aebi C, Fisch U, et al. Higher cord blood levels of mannose-binding lectin-associated serine protease- 2 in infants with necrotising enterocolitis. Pediatr Res 2008;64:562-6.

19. Frakking FN, Brouwer N, Zweers D, et al. High prevalence of mannosebinding lectin (MBL) deficiency in premature neonates. Clin Exp Immunol 2006;145:5-12.

20. Uemura K, Saka M, Nakagawa T, et al. L-MBP is expressed in epithelial cells of mouse small intestine. J Immunol 2002;169:6945-50.

21. Muller S, Schaffer T, Flogerzi B, et al. Mannan-binding lectin deficiency results in unusual antibody production and excessive experimental colitis in response to mannose-expressing mild gut pathogens. Gut 2010;59:1493-500.

22. Casanova JL, Abel L. Human mannose-binding lectin in immunity: friend, foe, or both? J Exp Med 2004;199:1295-9.

23. Frakking FN, Brouwer N, van Eijkelenburg NK, et al. Low mannosebinding lectin (MBL) levels in neonates with pneumonia and sepsis. Clin Exp Immunol 2007;150:255-62.

24. Auriti C, Prencipe G, Inglese R, et al. Role of mannose-binding lectin in nosocomial sepsis in critically ill neonates. Hum Immunol 2010; $71: 1084-8$.

25. Hart ML, Ceonzo KA, Shaffer LA, et al. Gastrointestinal ischemiareperfusion injury is lectin complement pathway dependent without involving C1q. J Immunol 2005;174:6373-80.

26. Walsh MC, Bourcier T, Takahashi K, et al. Mannose-binding lectin is a regulator of inflammation that accompanies myocardial ischemia and reperfusion injury. J Immunol 2005; 175:541-6.

27. Young CM, Kingma SD, Neu J. Ischemia-reperfusion and neonatal intestinal injury. J Pediatr 2011;158:e25-8.

28. Rajagopalan R, Salvi VP, Jensenius JC, et al. New insights on the structural/functional properties of recombinant human mannan-binding lectin and its variants. Immunol Lett 2009;123:114-24. 